\title{
ANALISIS ISI SENSASIONALISME BERITA KRIMINAL (STUDI KASUS PROGRAM INEWS DAN KOMPAS SULSEL)
}

\author{
MITHA MAYESTIKA KUEN, S.I.P, M.I.Kom, /YUWENI PUJI SAPUTRI,S.I.Kom \\ FISIPOL UNIVERSITAS INDONESIA TIMUR /Dosen \\ Email :mithakuen@gmail.com
}

\begin{abstract}
This study discusses the Analysis of the Content of Sensationalism in Criminal News (Case Study of the Inews Program of South Sulawesi and KompasSulsel). The basis of this research began because of the fierce competition between television, newspapers and radio and the limitations of the medium, making television shift from the emphasis on public conversation leading to entertainment. There was a tight competition in the Market News. This condition provides an increase in a phenomenon called "sensationalism". Criminal news is classified into sensational news because the topics and images displayed include sensationalism. In addition, criminal news also has the ability to attract the attention of the public. This study aims to compare the level of sensationalism in news programs, especially criminal news on InewsTv and KompasTv, through the InewsSulsel and KompasSulsel programs. From these comparisons, the research method used is content analysis by comparing messages from different sources. This can be seen in the news of Inews-Sulsel and Kompas-Sulsel which are packaged with the selection of certain words in the title, the use of graphics, interesting drawings and information, the borrowing of expert mouths to convey ideas, angle setting for media presentation, music use, songs and repetitive effects so that they are familiar and determine the agenda agenda [agenda setting]. The results showed that the Inews-sulsel news program was more sensational in presenting news about the chaotic case of the Kingdom of Gowa compared to the Kompas-sulsel program.
\end{abstract}

Keywords: Analysi; Sensationalism; Criminal News; Television News

\begin{abstract}
ABSTRAK
Penelitian ini membahas tentang Analisis Isi Sensasionalisme Berita Kriminal (StudiKasus Program Inews Sulsel Dan Kompas Sulsel). Dasar Penelitian ini berawal karena Kompetisi yang sengit antara televisi, koran dan radio serta adanya keterbatasan medium, membuat televisi bergeser dari penekanan terhadap percakapan publik mengarah pada hiburan. Terjadilah kompetisi dalam Market News yang ketat. Kondisi ini memberikan peningkatan terhadap sebuah fenomena yang dinamakan"sensasionalisme".Berita kriminal digolongkan kedalam berita sensasional karena topik dan gambar yang ditampilkan termasuk sensasional, Selain itu, berita kriminal juga memiliki kemampuan untuk menarik perhatian khalayak. Penelitian ini hendak membandingkan tingkat sensasionalisme dalam program beritakhususnyaberitakriminal di InewsTvdanKompasTv, lewat program InewsSulseldanKompasSulsel. Dari perbandingantersebut, Metode penelitian yang digunakan adalah analisis isi dengan membandingkan pesan dari sumber yang berbeda.Hal tersebut tampak pada berita Inews-sulsel dan Kompas-sulsel yang dikemas dengan pemilihan kata - kata tertentu pada judul, penggunaan grafis, gambar dan keterangan yang menarik, peminjaman mulut pakar untuk menyampaikan sebuah gagasan, penetapan angle untuk sajian media, penggunaan musik, lagu dan efek berulang - ulang sehingga familiar serta penentuan agenda
\end{abstract}


diskusi [agenda setting]. Hasil penelitian menunjukkan bahwa program berita Inewssulsel lebih sensasional dalam menyajikan berita kasus Kisruh Kerajaan Gowa dibandingkan dengan program Kompas-sulsel.

\section{Kata kunci : Analisis, Sensasionalisme, Berita Kriminal, Berita Televisi}

BAB I

\section{PENDAHULUAN}

\section{A. Latar Belakang}

Kompetisi yang sengit antara televisi, koran dan radio serta adanya keterbatasan medium, membuat televisi bergeser dari penekanan terhadap percakapan publik mengarah pada hiburan. Televisi telah membuat hiburan sebagai format dasar penggambaran segala sesuatu.

Hiburan merupakan supraideologi segala diskursus dalam televisi. Tayangan televisi dibuat seringkali didefinisikan sebagai dorongan untuk praktik jurnalistik sensasional.

Berita sensasional dibuat untuk menarik perhatian atas nama rating penonton yang tinggi (Berkowitz \& Gobetz, 1993;1992).

Salah satu jenis berita televisi yang tergolong sensasional adalah berita kriminal (Zhou, 2001). Berita kriminal digolongkan kedalam berita.

sensasional karena topik dan gambar yang ditampilkan termasuk sensasional. Selain itu, berita kriminal juga memiliki kemampuan untuk menarik perhatian khalayak.

Berdasarkan hasil analisa yang dilakukan (NewHagen \& Grimm, 1998;1996), berita kriminal mampu membangkitkan respon neural pada khalayak. Misalnya saja memprovokasi emosi seperti rasa takut, perasaan terasing, maupun luapan rasa gembira. Peliputan yang hebat mengenai kejahatan juga menimbulkan kesan pada penonton bahwa kejahatan merajalela di sekitar mereka (Septian, 2005)

Suatu berita dikatakan sensasional ketika berita tersebut untuk menghibur dan menyenangkan penonton.Hal yang terpenting dari televisi adalah orangorang menontonnya (Postman, 1995).Saat ini informasi dibuat lebih atraktif atau berorientasi pada hiburan,caranya dengan membuat informasi semakin "sensasional" atau menyerupai tabloid dari waktu ke waktu (Uribe \& Gunter, 2007).

Market driven journalism terbukti meningkatkan kebutuhan akan program berita yang menarik perhatian penonton. Motif keuntungan

dapat menghibur dan menarik perhatian Khalayak (Zhou, 2001). Perhatian penontonterhadap berita kiriminal pada program lokal didasari oleh adanya hubungan kedekatan baik secara emosional maupun letak geografisnya.

Siaran televisi lokal seperti KompasTV dan InewsTV Makassar, tidak terlepas dari tayangan tayangan yang memberitakan mengenai kasuskekerasan atau kejahatan yang terjadi di wilayah sulawesi selatan ataukota Makassar khususnya. Berita kriminal yang ditayangkan di program televisi lokal Makassar cukup sensasional karena menarik perhatian penonton atau pemirsa yang bermukim di wilayah Makassar atau sekitarnya.

Sebagai stasiun televisi swasta yang memfokuskan siarannya pada program berita, Inews Tv dan Kompas $\mathrm{Tv}$ tentu mengarahkan berita yangdisajikan menjadi lebih sensasional, sehingga dapat menarik perhatian khalayak. Oleh karenanya, penelitian ini hendak membandingkan

tingkatsensasionalisme dalam program berita khususnya berita 
kriminal di Inews Tv dan Kompas Tv, lewat program Inews Sulsel dan Kompas Sulsel. Dari

perbandingan tersebut, dapat dilihat bagaimana strategi pengemasan berita yang dilakukan oleh masing masing program dalam menghadapi persaingan pasar. Berdasarkan pemikiran tersebut, penulis tertarik untuk melakukan penelitian dengan mengangkat judul "ANALISIS ISI SENSASIONALISME BERITA KRIMINAL (STUDI KASUS PROGRAM INEWS SULSEL DAN KOMPAS SULSEL).

\section{B.Rumusan Masalah}

Berdasarkan uraian pada latar belakang di atas, maka dirumuskan permasalahan penelitian sebagai berikut :

1. Bagaimana Pola penyajian pemberitaan kriminalitas dalam program Inews Sulsel dan Kompas Sulsel?

2. Bagaimana kecenderungan tingkat sensasionalisme dalam pemberitaan kriminalitas pada program berita Inews Sulsel dan Kompas Sulsel?

\section{C.Tujuan Penelitian}

Berdasarkan rumusan masalah yang telah dikemukakan sebelumnya, maka tujuan dari penelitian ini :

1. Untuk mengetahui pola penyajian pemberitaan kriminalitas pada program berita Inews Sulsel dan Kompas Sulsel.

2. Untuk mengetahui ada/tidaknya kecenderungan tingkat sensasional dalam berita kriminal pada program berita Inews Sulsel dan Kompas Sulsel.

\section{D.Manfaat Penelitian}

Berdasarkan pada latar belakang masalah, rumusan masalah, dan tujuan penelitian, adapun yang menjadi manfaat dilakukan penelitian ini terdiriatas beberapa manfaat, diantaranya :

1.Manfaat Teoritis :

Menambah pengetahuan bagi ilmu komunikasi terutama jurnalisme siar mengenai konsep sensasionalisme dalam berita televisi. Memperkaya penelitian dengan konsep sensasionalisme beritatelevisi yang menggunakan content analysis sehingga dapat menjadi acuan untuk penelitian lain yang lebih mendalam.

\section{Manfaat Praktis :}

Penelitian ini diharapkan bisa menambah kajian ilmiah tentang pemberitaan televisi, terutama mengenai berita kriminal.

Penelitian ini diharapkan dapat menjadi referensi bagi program berita dari stasiun televisi yang bersangkutan dalam menjalankan fungsinya sebagai agen informasi.

Penelitian ini diharapkan bisa memberikan gambaran tentang sikap pemberitaan televisi terhadap isu perempuan.

Dalam penlitian ini, penulis akan menggunkaan terminologi 'sensasionalisme' yang didasarkan pada penelitian oleh Shuhua Zhou tahun 2001 yang didukung pula dengan dua rekannya (Grabe \& Barnett, 2001). Penelitian Vettehen dan Nuijten yang meneliti sensasionalisme pada program berita televisi di Belanda juga akan digunakan untuk membangun instrumen penelitian ini.

\section{METODE PENELITIAN}

\section{A. Waktu dan Lokasi Penelitian}

Waktu penelitian akan dilaksanakan selama 2 (dua) bulan. Adapun lokasi penelitian ini adalah pada Stasiun Televisi Inews $\mathrm{Tv}$ Makassar dan Kompas Tv Makassar.

Alasan penulis menggunakan Program Inews-Sulsel dan KompasSulsel karena kedua program ini merupakan program daerah dari dua Televisi Swasta Nasional yang sudah memiliki nama besar di masyarakat Indonesia.

\section{B. Jenis Penelitian}

Penelitian ini menggunakan pendekatan kuantitatif. Analisis pendekatan kuantitatif melibatkan aktivitas perhitungan yang hasilnya 
dijabarkan secara numerik atau dalam bentuk angka - angka untuk menjawab rumusan pertanyaan atau masalah penelitian (Mulyana, 2007).

Ciri - ciri utama penelitian kuatitatif (Irawan, 2006) antara lain :

1. Permasalahan penelitian terbatas dan sempit

2. Mengikuti pola berpikir deduktif

3. Mempercayai angka (statistika atau matematika) sebagai instrumen untuk menjelaskan kebenaran

4. Membangun validitas internal dan validitas eksternal sebaik mungkin.

Pendekatam penelitian

kuantitatif dipilih karena hasil Tabel

Prorgram Berita dan Jumlah Paket Berita Kriminal

\begin{tabular}{|l|l|l|}
\hline No & Program Berita & $\begin{array}{l}\text { Jumlah } \\
\text { Paket Berita } \\
\text { Kriminal }\end{array}$ \\
\hline 1. & Inews - Sulsel & $\begin{array}{l}12 \text { paket } \\
\text { berita }\end{array}$ \\
\hline 2. & $\begin{array}{l}\text { Kompas } \\
\text { Sulsel }\end{array}$ & $\begin{array}{l}11 \text { paket } \\
\text { berita }\end{array}$ \\
\hline & Total & $\begin{array}{l}23 \text { paket } \\
\text { berita }\end{array}$ \\
\hline
\end{tabular}

Sumber : Inews TV Makassar \& Kompas TV Makassar

Sampel adalah bagian anggota populasi yang diambil melalui prosedur tertentu sehingga mewakili populasinya. Pengambilan sampel sangat dipengaruhi oleh unit analisis serta populasinya. Paket berita kriminalitas dari program Inews Sulsel dan Kompas sulsel menjadi unit analisis dalam penelitian ini.

Teknik penarikan sampel digunakan untuk mengumpulkan informasi yang dapat dimanfaatkan untuk menjawab permasalahan peneltian secara objektif. Teknik penarikan sampel dilakukan melalui berupa angka dapat dikatakan cukup valid untuk mengukur tingkat sensasionlaisme program berita Inews Sulsel dan Kompas Sulsel dalam berita kriminalitas.

\section{Populasi dan Sampel}

Populasi dalam penelitian ini adalah Program Berita Inews Sulsel (InewsTV) dan Kompas Sulsel (KompasTV) yang memuat berita kriminal mengenai kasus Kisruh Kerajaan Gowa dan DPRD Gowa, yang mengakibatkan bentrok antar warga Kabupaten Gowa serta berujung pada pembakaran kantor DPRD Gowa yang dilakukan oleh beberapa oknum.

perekaman paket berita. Paket berita tersebut kemudian dibedah dengan metode analisis isi (content analysis), yang kemudian dikoding berdasarkan indikator yang telah dirumuskan sebelumnya. Pengambilan sampel dalam penelitian ini secara non probabilitas. Sampel dalam penelitian ini adalah populasi atau seluruh total paket berita kriminal yang ditayangkan di Inews Sulsel dan Kompas Sulsel ( sejak januari 2017 ).

\section{Sumber Data}

Jenis data dalam penelitian ini ada 2 (dua) yaitu:

1. Data primer adalah data yang diperoleh dari pengamatan secara langsung dan mengadakan wawancara langsung dengan informan yang berkaitan dengan masalahyang dibahas untuk memperoleh data yang sebenarnya.

2. Data sekunder adalah data yang bersumber dari hasil penelitian pustaka dan dokumen - dokumen serta informasi tertulis lainnya yang berkaitan dengan pokok pembahasan.

E. Teknik Pengumpulan Data 
Teknik pengumpulan data yang digunakan dalam penelitian ini terdiri dari :

1. Observasi

Penulis mengadakan pengamatan dan pencatatan secara sistematika dan langsung terhadap gejala yang tampak pada objek penelitian. Dalam hal ini penulis mengadakan pengamatan untuk mendapatkan informasi mengenai keadaan objek dan sarana dan prasarana.

2. Dokumen

Jenis dokumen yang dikumpulkan dalam penelitian ini adalah dokumen resmi internal di lokasi penelitian, sumber data berupa struktur organisasi, dan informasi lainnya.

\section{Wawancara}

Teknik pengumpulan data ini digunakan bila peneliti ingin melakukan studi pendahuluan untuk menemukan permasalahan yang harus diteliti dan juga mengetahui hal - hal dari responden secara lebih mendalam serta jumlah reponden sedikit.

\section{F. Teknik Analisis Data}

Untuk menganalisis data yang telah diperoleh maka teknik yang digunakan adalah teknik analisis deskriptif. Dalam penelitian ini, penulis berusaha melakukan pengukuran yang cermat terhadap fenomena sosial tertentu dengan mengembangkan konsep dan menghimpun fakta, namun tidak melakukan pengujian hipotesa (Greenfield, 1996, h.131).

Penulis menggunakan analisis isi deskriptif untuk menggambarkan secara detail suatu pesan, atau suatu aspek teks tertentu. Analisis isi deskriptif tidak dimaksudkan untuk menguji suatu hipotesa tertentu, atau menguji hubungan diantara variabel.

Penelitian ini bertujuan

mendeskripsikan pola

sensasionalisme dan tingkat sensasionalisme dalam dimensi isi di
Inews-Sulsel dan Kompas-Sulsel. Untuk mendeskripsikannya, disediakan ukuran - ukuran tertentu yang berasal dari konsep - konsep yang digunakan. Setelah itu, hasil keduanya akan dibandingkan untuk melihat program berita mana yang memiliki tingkat sensasionalisme yang jauh lebih besar. Penelitian ini tidak bertujuan untuk melakukan generalisasi, namun penjelasan perindikator yang mengasosiasikan hal tertentu.

\section{G. Operasional Variabel}

1. Defenisi Operasional

a) Format Pola penyajian Berita (Baksin, 2006)

Format VO/SOT,VO/SOT yaitu format berita TV yang memadukan voice over (VO) dan sound on tape (SOT). Lead in dan isi tubuh berita dibacakan presenter. Lalu diakhir berita dimunculkan soundbite dari narasumber sebagai pelengkap dari berita yang telah dibacakan sebelumnya. Format VO/SOT dipilih jika gambar yang ada kurang menarik atau kurang dramatis, namun ada pernyataan narasumber yang perlu ditonjolkan untuk menlengkapi narasi pada akhir berita. Total durasi tidak lebih dari 60 detik, dimana sekitar 40 detik untuk VO dan 20 detik untuk soundbite.

Format Paket (package)Adalah laporan berita lengkap dengan narasi yang direkam dalam pita kaset. Narasi dalam paket dibacakan oleh seorang pengisi suara yang biasanya adalah reporter atau penulis berita (writer). Kebanyakan berita TV dihadirkan dalam format ini. Rata - rata durasi sebuah paket dalam suatu program berita 1,45 menit hingga 2,5 menit. Tentu saja ada paket yang berdurasi lebih lama, misalnya 5 menit, atau bahkan 30 menit untuk sebuah laporan khusus.

2. Sensasionalisme berita (Vettehen, 2006) :

Dimensi Isi 
Instrumen - instrumen dimensi isi digunakan untuk melihat unsur unsur sensasional yang terkadang ada dalam isi berita. Dalam dimensi isi terdapat subdimensi dan indikator indikator :

a) Penggunaan Suara Natural

Suara natural adalah suara yang masuk ke dalam rekaman gambar saat proses pengambilan gambar berlangsung.

1) Penggunaan narasumber yang menarik perhatin

Subdimensi penggunaan narasumber terbagi menjadi tiga indikator, yaitu :Narasumber Politisi, Narasumber Ahli ,Narasumber Warga (layperson)

2) Penampilan Emosi Berdasarkan

teori

psokologi, subdimensi penampilan emosi terbagi menjadi empat macam emosi 'dasar' yang dikemukakan oleh (Kruger, 1996), yaitu :

Kegembiraan(subindikator;orang tertawa, cerita, senyum), Kesedihan (subindikator; orang menangis, bermimik muram), Ketakutan (subindikator; orang panik), Kemarahan (subindikator; orang berteriak-riak).

b) Konsep Operasional

Penulis menentukan bahwa suatu indikator dikatakan sensasional apabila persentase penggunaannya lebih dari 45\% (persentase setengah dari total sampel paket berita Kriminal).

\section{A. Analisis Program Berita Inews Sulsel dan Kompas Sulsel}

Pada berita mengenai kisruh Raja Gowa, terdapat berbandingan yang terlihat antara kedua program berita Inews Sulsel dan Kompas Sulsel. Perbedaan tersebut berupa jumlah paket berita yang ditayangkan selama kurang lebih 1 bulan (11 - 27 september 2016). Paket berita mengenai Kisruh Raja Gowa yang ditayangkan di program berita Inews
Sulsel jumlahnya lebih banyak daripada paket berita mengenai Raja Gowa yang ditayangkan di Kompas Sulsel. Inews Sulsel menayangkan 12 paket berita Kisruh Raja Gowa, sementara Kompas Sulsel menayangkan 11 paket berita saja dan diposting pada akun Youtube KompasTV Makassar.

Perbedaan jumlah paket berita ini dikarenakan Kompas Sulsel banyak menayangkan berita berita sosial dan kriminal yang bersifat situasional, serta berita - berita yang bersifat unik. Porsi berita tersebut lebih besar dibanding pemberitaan kriminalitas, politik dan hukum yang terasa memberatkan penonton (membutuhkan kepintaran untuk mencernanya).

Sebaliknya, Inews-Sulsel memiliki porsi pemberitaan yang lebih besar terhadap kasus hukum yang terjadi di sulawesi selatan. Inews-Sulsel juga meayangkan paket berita yang unik, namun porsi pemberitaannya tidak sebanyak Kompas-Sulsel. Berita - berita yang ditampilkan Inews-Sulsel terkesan "lebih berbobot" dengan porsi berita politik serta hukum yang lebih banyak.

Selain dari perbedaan jumah paket berita,perbedaan lain juga terdapat dalam cara pengemasan (gaya pengeditan dari redaksi) dan penayangannya. Inews-Sulsel sering sekali (banyak) menggunakan efek transisional dalam perpindahan dari satu shot ke shot berikutnya. Hampir seluruh efek transisional dan non transisional digunakan dalam paket berita Kisruh Gowa di Inews-Sulsel. Sebaliknya, Kompas-Sulsel jarang seklai (hanya sedikit) menggunakan efek transisional dan efek non transisional dalam pengemasan paket beritanya. Seluruh paket berita Kompas-Sulsel menggunakan tekik cut to cut untuk perpindahan antar shot. 


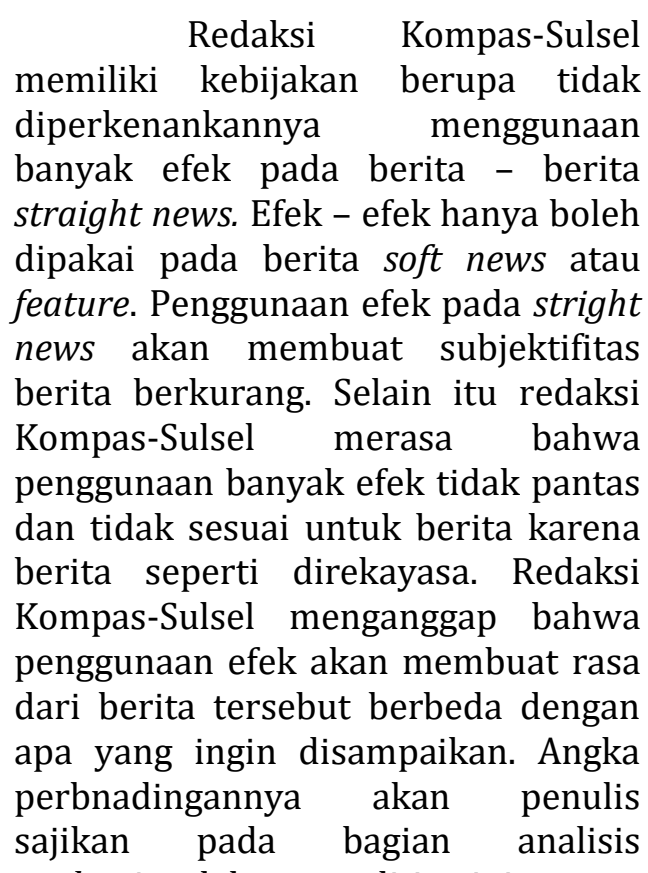
packaging dalam penelitian ini.

\section{B. Analisis Dimensi Isi}

1. Keberadaan Suara Natural Suara natural adalah suara yang bersifat dramatis yang masuk ke dalam rekaman gambar saat proses pengambilan gambar berlangsung. Misalnya saja tangisan atau teriakan subjek dalam berita, maka kemunculan suara natural dihitung. Jika suara - suara ini masuk ke dalam berita maka berita tersebut dikatakan sensasional.

Semakin sering suara natural yang dramatis terdapat dalam paket berita, maka semakin sensasional berita tersebut. Baik Inews-Sulsel dan Kompas-Sulsel menggunkaan suara natural pada paket beritanya. Menurut (Vettehen, News is an Age of Competition: Sensasionalism, 2006)keberadaan suara natural akan menambah tingkat sensasionlaisme berita. Berita dengan suara natural akan lebih menarik perhatian masyarakat (penonton).

Berikut ini tabel perbandingan keberadaan suara natural paket berita Kisruh Gowa pada Inews-Sulsel dan Kompas-Sulsel:

Tabel
Perbandingan Keberadaan Suara NaturalPaket Berita Kisruh Raja Gowa Pada Inews TV dan Kompas TV

\begin{tabular}{|l|l|l|}
\hline Keterangan & $\begin{array}{l}\text { INews } \\
\text { TV }\end{array}$ & $\begin{array}{l}\text { Kompas } \\
\text { TV }\end{array}$ \\
\hline $\begin{array}{l}\text { Ada suara } \\
\text { natural }\end{array}$ & $\begin{array}{l}12 \\
\text { paket } \\
\text { berita } \\
(100 \%)\end{array}$ & $\begin{array}{l}8 \\
\text { paketberi } \\
\text { ta } \\
(72,8 \%)\end{array}$ \\
\hline $\begin{array}{l}\text { Tidakadasu } \\
\text { ara natural }\end{array}$ & $\begin{array}{l}3 \text { paket } \\
\text { berita } \\
(27,2 \%)\end{array}$ \\
\hline Total & $\begin{array}{l}12 \\
\text { paket } \\
\text { berita } \\
(100 \%)\end{array}$ & $\begin{array}{l}11 \text { paket } \\
\text { berita } \\
(100 \%)\end{array}$ \\
\hline
\end{tabular}

Sumber : Inews TV Makassar \& Kompas TV Makassar

Berdasarkan pengunaan suara natural dalam paket berita, baik Inews Sulsel maupun Kompas Sulsel sama - sama mengunakan suara natural dalam porsi cukup besar pada paket beritanya. Keduanya memiliki persentase penggunaan suara natural yang melebihi $45 \%$, artinya dalam penggunaan suara natural kedua paket berita di kedua program termasuk sensasional. Akan tetapi, persentase keberadaan suara natural Inews-Sulsel $\quad 100 \% \quad$ sementara Kompas Sulsel 72,8\%, sehingga dapat dikatakan bahwa Inews-sulsel lebih sensasional daripada Kompas-sulsel dalam penggunaan suara natural.

Keberadaan suara natural yang terkesan dramatis pada paket berita kedua program, baik Inewssulsel maupun Kompas-Sulsel antara lain; (1) Teriakan polisi untuk menghentikan aksi bentrok, (2) suara ledakan, (3) suara beberapa warga yang menyuruh untuk berhenti melempar kepada aparat kepolisian, (4) teriakan masyarakat yang menuntut pemerintaha Kabupaten Gowa, (5) teriakan warga yang saling bentrok. Paket berita dengan suara 
natural teriakan warga saat melakukan aksi bentrok memiliki porsi yang paling besar dibanding dengan suara natural lain.

Sementara itu, suara natural yang terdapat dalam paket berita Kompas-Sulsel antara lain; (1) teriakan wartawan meminta keterangan, (2) suara kobaran api, (3) suara ledakan, (4) suara bentrok antar warga.

Berbeda dengan suara natural pada paket berita Inews-Sulsel yang berjumlah lima jenis, Kompas-Sulsel memiliki paket berita dengan jenis suara natural yang lebih sedikit yaitu empat jenis. Selain itu Kompas-Sulsel memiliki porsi yang cukup besar dengan suara natural teriakan wartawan saat meminta informasi kepada beberapa narasumber. Meski Kompas-Sulsel memiliki jenis suara natural yang lebih sedikit, namun persentase penggunaannya lebih besar dibandingkan dengan InewsSulsel.

2. Penggunaan Narasumber Penggunaan narasumber terbagi menjadi tiga macam diantaranya; politisi, ahli, dan masyarakat umum atau layperson. Keberadaan narasumber politisi dan ahli dianggap dapat menurunkan sensasional karena tidak menambah unsur kedekatan (proximity). Sebaliknya dengan penggunaan narasumber Layperson. Keberadaan narasumber Layperson akan menambah tingkat sensasionalisme dalam berita.

Hal ini karena khalayak (penonton) merasa adanya kedekatan dengan berita yang menggunkaan narasumber layperson. Paket berita yang dilengkapi narasumber dianggap lebih menarik perhatian khalayak. Dalam penelitian ini, yang dimaksud dengan narasumber politisi adalah orang - orang yang berada di kursi pemerintahan politik seperti Presiden, anggota MPR/DPR, menteri, dan sebaginya. Sementara itu, narasumber ahli adalah orang - orang yang memiliki pengetahuan khusu dalam suatu hal.

Narasumber ahli dan politisi dalam politisi dalam paket berita Inews-sulsel, diantaranya; (1) Pihak Kepolisian, (2) sejarawan, (3) Gubernur Sulsel, (4) Lembaga Adat, (5) Polda Sulsel.

Inews-Sulsel memiliki jenis narasumber politisi dan ahli yang cukup beragam, yaitu tujuh jenis. Dari keseluruhan penggunaan narasumber politisi dan ahli, paket berita yang menggunkaan narasumber ahli dari pihak kepolisian paling besar jumlahnya yaitu empat orang. Paket berita yang menggunakan narasumber ahli berupa sejarawan juga dihadirkan.

Kompas-Sulsel juga menghadirkan narasumber dari pihak kepolisian, namun jumlahnya hanya tiga orang. Akan tetapi, Kompas-Sulsel memiliki kesamaan dengan Inewssulsel yaitu penggunaan pihak kepolisian sebagai narasumber ahli paling banyak dibandingkan dengan narasumber lain. Terdapat kesamaan penggunaan Gubernur Sulsel dalam menanggapi Kasus yang terjadi di Kabupaten Gowa. Narasumber ahli dan politisi dalam paket berita Kompas-Sulsel, diantaranya : (1) Pihak kepolisian, (2) Gubernur Sulsel, (3) Anggota Legislatif.

Narasumber yang juga terdapat dalam suatu berita adalah narasumber layperson (warga biasa). Narasumber layperson adalah narasumber yang menentukan tingkat sensasionlaisme dalam suatu berita (narasumber sensasional).

persentase penggunaan narasumber non sensasional yaitu narasumber politisi dan ahli Inewssulsel dan Kompas-sulsel lebih besar $(77,8 \%)$ daripada Kompas-sulsel $(66,7 \%)$. Persentase narasumber non sensasional ini lebih dari 45\%, artinya penggunaan narasumber ahli dan politik membuat kedua program 
berita kurang sensasional. Selain itu, persentase penggunaan narasumber sensasional berupa narasumber layperson pada program berita Kompas-sulsel hanya 33,4\%, sementara Inews-sulsel sebesar $22,2 \%$. Oleh karena itu, dapat disimpulkan bahwa dalam indikator penggunaan narasumber, kedua program berita Kompas-sulsel dan Inews-sulsel kurang sensasional dalam penggunaan narasumber.

\section{Penampilan Emosi}

Dalam subdimensi penampilan emosi, menurut Kruger (1996) terdapat empat indikator yang terdiri dari empat macam emosi 'dasar' antara lain; kegembiraan (orang tertawa, ceria, senyum), kesedihan (oang menangis, bermimik muram), ketakutan (orang panik), dan kemarahan (orang berteriak - teriak ).

Penamapilan emosi adalah indikator terakhir dalam dimensi isi yang menentukan tingkat sensasionalisme berita. Penampilan emosi yang dijadikan indikator bukan hanya berasal dari emosi yang ditampilkan oleh narasumber, melainkan emosi yang ditampilkan oleh seluruh subjek utama dalam gambar atau berita yang sedang ditayangkan.

Dalam penelitian ini, penulis menemukan emosi dari subjek gambar berupa ketakutan,kesedihan dan kemarahan. Penulis hanya menemukan emosi ketakutan beberapa masyarakat yang menyaksikan kebakaran kantor DPRD Kabupaten Gowa.

Jika diakumulasi, total perbandingan kemunculan penampilan emosi ketakutan, kesedihan, kemarahan dan kegembiraan dalam paket berita Kisruh Gowa.

Dalam paket berita Kisruh Gowa di Inews-sulsel, emosi kemarahan berasal dari masyarakat yang tengah melakukan aksi saling bentrok dan lempar batu. Juga beberapa masyarakat yang melakukan aksi menuntut polda sulsel untuk mengusut tuntas kasus yang sedang terjadi tersebut.

Persentase penampilan emosi Inews-sulsel dan Kompas-sulsel lebih dari 90\%, artinya dalam indikator penampilan emosi kedua program berita termasuk sensasional. Akan tetapi, persentase Inews-sulsel sebesar 91,6\% atau lebih sensasional dibandingkan dengan Kompas-sulsel yang sebesar $91 \%$.

\section{C.Analisis Dimensi Format}

Berdasarkan definisi konseptual dan instrumen penelitian, analisis pada dimensi format akan dibagi ke dalam dua jenis yaitu teknik kamera dan penggunaan efek, antara lain sebagai berikut :

1. Teknik Kamera

Eyewitness Camera

Eyewitness Camera adalah teknik dimana kamera diletakkan dipundak camera person sehingga penonton merasa bahwa kamera tersebut adalah mata penonton. Penonton seolah - olah merasa berada di lokasi kejadian (Vettehen, 2006). Pada penelitian ini, teknik eyewitness camera dihitung dengan mencatat jumlah dan interval waktu kemunculan eyewitness camera satu ke eyewitness camera berikutnya. Semakin banyak jumlah eyewitness camera dalam suatu paket berita maka semakin besar tingkat sensasionalisme. Sementara itu untuk interval waktu, semakin kecil interval waktu kemunculan eyewitness camera ke kemunculan eyewitness camera berikutnya, maka semakin besar tingkat sensasionalisme berita tersebut.

Berikut ini perbandingan jumlah dan interval waktu eyewitness camera dalam berita kisruh Gowa :

Berdasarkan perbandingan persentase jumlah dan interval waktu kemunculan eywitness camera dalam paket berita Inews-sulsel dan 
Kompas-sulsel, dapat dikatakan bahwa kedia program berita sama sama sensasional. Akan tetapi, persentase jumlah penggunaan eyewitness camera Inews-sulsel lebih besar (75\%) dibandingkan dengan Kompas-sulsel yang $(72,2 \%)$. Selain itu interval waktu Inews-sulsel juga lebih kecil dibandingkan dengan Kompas-sulsel. Sehingga Inews-sulsel lebih sensasional.

Dalam paket berita Inewssulsel bnayak ditemukan eyewitness camera terhadap pengambilan gambar beberapa masyarakat yang melakukan aksi penuntutan terhadap pemerintah dan polri. Eyewitness camera juga hadir ketika pengambilan gambar aksi saling lempar batu antar warga, kameramen terus mengikuti gerakan warga yang saling kejar dan melempar agar memperoleh gambarnya dengan jelas. Suasana dimana penonton di rumah merasa terlibat langsung dengan yang ditampilkan di layar TV juga sering muncul saat paket berita saat gedung DPRD Gowa terbakar. Eyewitness camera juga tampak saat pengambilan gambar Balla Lompoa dari halaman depan.

Kompas-sulsel juga memiliki teknik eyewitness camera pada paket berita bentroknya warga Gowa. Tayangan berita Kompas-sulsel menunjukan pengambilan gambar yang mengikuti gerakan saling lempar batu antar warga. Selain itu, eyewitness camera pada Kompassulsel juga tampak di paket berita terbakarnya kantor DPRD Gowa.

Eyewitness camera tidak dapat dihindari ketika objek gambar bergerak (tidak statis). Kameramen harus mengikuti dan mengejar gerakan objek agar tetap dapat ditangkap kamera. Kondisi dimana objek bergerak memang tidak menguntungkan bagi kameramen, namun eyewitness camera terbukti menarik perhatian penoton karena penonton di rumah merasa bahwa kamera tersebut adalah mata mereka. Sehingga penonton di rumah merasa terlibat langsung dengan apa yang ditampilkan di layar TV (Vettehen, 2006). Semakin banyak kemunculan eyewitness camera dalam suatu paket berita, maka berita tersebut dikatakan semkain sensasional.

Perspektif Kamera

Penggunaan perspektif kamera juga mempengaruhi tingkat sensasionalisme suatu berita. Ada tiga jenis perspektif kamera, antara lain : high angle, eye level, dan low angle. High angle merupakan pengambilan gambar dari atas objek yang menimbulkan kesan 'lemah','tak berdaya', 'kesendirian', dan kesan lain ynag mengandung konotasi 'dilemahkan atau dikerdilkan'. Keberadaan high angle akan menambah tingkat sensasionalisme. Eye level adalah teknik pengambilan gambar yang sejajar dengan objek. Keberadaan eye level tidak berpengaruh terhadap indikasi sensasionalisme. Low angle, yaitu pengambilan gambar dari bawah objek. Sama seperti high angle, perspektif ini juga akan menambah tingkat sensasionalisme.

Berikut ini adalah total perbandingan penggunaan seluruh perpektif kamera Inews-sulsel dan Kompas-sulsel :

Total perbandingan High Angle Inews TV 2 Paket (16 kali) sedangkan Kompas Tv 1 paket ( 9 kali), Eye Level 6 paket (10 kali) untuk Inews Tv dan Kompas Tv 5 paket (11 kali), Low Angle 5 paket untuk kedua TV namun Inews TV (28 kali) sedangkan Kompas TV (17 Kali).

Data Sumber : Inews TV Makassar \& Kompas TV MakassarPerspektif kamera high angle dan low angle memengaruhi tingkat sensasionalsime suatu berita. Sementara eye level tidak mempengaruhi atau termasuk kedalam indikator non sensasional. Dalam penelitian ini, penulis 
memperoleh hasil bahwa berdasarkan penjumlahan persentase perspektif kamera, Kompas-sulsel lebih sensasional dibandingka dengan Inews-sulsel.

\section{Editing}

penulis menggunakan instrumen sub dimensi editing yang digunakan Vettehen. Dalam penelitiannya, Vettehen menggunakan empat indikator (fade, disolve, slow motion, repeating images).

Berdasarkan persentase penggunaan efek repeating of image, Inews-sulsel memiliki persentase yang lebih besar yaitu $75 \%$, sementara Kompas-sulsel sebesar 54,5\%. Oleh karena itu, Inews-sulsel lebih sensasional daripada Kompas-sulsel.

D. Interpretasi Data

Perbandingan Sensasionalisme antara Inews TV dan Kompas TV

Penelitian ini bertujuan untuk membandingkan tingkat sensasionalisme dalam program Inews-sulsel dan Kompas-sulsel saat meyangkan berita Kisruh Gowa. Penulis berusaha menjabarkan hasil analisis dengan membandingkan penggunaan indikator - indikator yang dapat mengukur sensasionalisme suatu berita. Indikator yang digunakan sesuai dengan penelitian terdahulu yaitu terbagi menjadi dua dimensi, dimensi isi dan dimensi format. Hasil analisis data menunjukkan bahwa Inewssulsel lebih sensasional dibandingkan dengan Kompas-sulsel.

Akan tetapi, jika dijabarkan berdasarkan perbandingan dimensi isi, Kompas-sulsel lebih sensasional dibandingkan dengan Inews-sulsel. Dalam hal penggunaan suara natural Kompas-sulsel lebih sensasional.

Kompas memiliki paket berita dengan penggunaan suara teriakan wartawan meminta keterangan dan suara kobaran api yang kencang dengan persentase yang lebih besar dibandingkan dengan Inews-sulsel.
Dalam indikator penggunaan narasumber, Kompas-sulsel dan Inews-sulsel dikatakan urang sensasional. Hali ini karena kedua program berita menampilkan banyak narasumber ahli dan politisi untuk memaparkan serta memberikan keterangan mengenai kasus tersebut. Selian itu penggunaan narasumber sensasional berupa narasumber layperson juga tidak memenuhi indikator sensasional.

Selain dilihat dari dimensi isi, dimensi format juga memperlihatkan perbedaan sensasionalisme antara Inews-sulsel dan Kompas-sulsel. apabila dilihat dari perbandingan dimensi format, maka Inews-sulsel lebih sensasional dibandingkan dengan Kompas-sulsel. Dalam penggunaan teknik eyewitness camera, Inews-sulsel sering menampilkannya dalam paket berita saat warga saling lempar dalam bentrok yang terjadi di Kabupaten Gowa. Teknik ini sering seklai digunkaan dan diulang dalam paket berita Inews-sulsel. Sementara Kompas-sulsel uga memiliki penggunaan teknik eyewitness camera yang sama saat paket berita yang sama, namun pengulangan pada beritanya tidak sebnayak Inewssulsel. Sehingga dapat dikatakan, Inews-sulsel lebih sensasional.

Dalam penggunaan indikator close up Inews-sulsel dan Kompassusel kurang sensasional karena sedikitnya penggunaan teknik ini dalam paket berita. Meski demikian, teknik ini selalu diaplikasikan saat mengambil wajah mawrga yang tengan melakukan aksi demostrasi. Shot paket berita inipun juga ditayangkan oleh Kompas-sulsel, naun jumlahnya tidak sebanyak Inewssulsel.

Pada teknik kamera suara yang ditambahkan saat editing, Inews-sulsel lebih sensasional daripada Kompas-sulsel. Hal ini karena paket berta Inews-sulsel 
menggunakan lagu - lagu dan sound effect yang cukup sering daripada reportase.

Dimensi format yang terakhir adalah teknik editing. Dalam penggunaan teknik editing, hasil analisis menunjukkan perbedaan yang nyata bahwa Inews-sulsel lebih banyak dan sering menggunakan efek transisionla dan efek non transisional dalam paket beritanya. Sementara Kompas-sulsel jarang (hanya beberapa) yang menggunakan teknik ini.

Apabila dilihat dari berbandingan seluruh dimensi, baik isi maupun format, maka Inews-sulsel lebih sensasional dibandingkan dengan Kompas-sulsel. Berdasarkan hasil penelitian ini, penulis menyimpulkan bahwa jika penggunaan semua indikator dalam dimensi isi dan dimensi format diakumulasi, maka terbukti bahwa Inews-sulsel lebih sensasional dibandingkan dengan Kompas-sulsel. Orientasi sensasionalisme Inewssulsel tampak pada penampilan emosi, penggunaan teknik eyewitness camera, penggunaan suara natural, penggunaan teknik zoom, dan pengemasan paket berita yang banyak menggunakan teknik editing. Sementara Kompas-sulsel memiliki orientasi sensasional pada penggunaan suara natural, perpektif kamera, dan rata - rata durasi per shot.

Sensasionalisme merupakan istilah untuk menyebutkan adanya penggunaan bahan - bahan atau metode - metode dalam rangka menciptakan unsur keterkejutan (shocks), hal - hl yang menarik (excite) atau hal - hal yang membangun keanehan (curiosity) bagi khalayak. Berita kisruh Raja Gowa menciptakan unsur - unsur tersebut diatas. Penonton dibuat terkejut dengan paket berita adanya saling serang antar masyarakat Gowa yang merupakan kali pertama terjadi dalam sepanjang sejarah di
Kabupaten Gowa. Tayangan berita inipun berujung pada pembakaran kantor DPRD Gowa yang kasus hukumnya berkepanjangan.

Penelitian ini memaparkan bahwa apabila berita televisi ingin memiliki daya tarik, Inews-sulsel dan Kompas-sulsel harus mencoba sebanyak mungkin melengkapi tayangannya. Hal tersebut tampak pada berita yang dikemas dengan pemilihan kata - kata tertentu pada judul, penggunaan grafis, gambar dan keterangan yang menarik, peminjaman mulut pakar untuk menyampaikan sebuah gagasan, penetapan angle untuk sajian media, penggunaan musik, lagu dan efek berulag - ulang sehingga familiar serta penentuan agenda diskusi [agenda setting]. Menurut Zhou, isi berita yang termasuk sensasional adalah yang menghibur dan menarik perhatian khalayak.

\section{A. Kesimpulan}

Dari hasil penelitian yang dilakukan pada bab sebelumnya mengenai tingkat sensasionalisme berita kriminal pada Inews TV dan Kompas TV Makassar, peneliti dapat menarik dan mengambil suatu kesimpulan sebagai berikut :

Pola penyajian berita pada Inews-suslsel dan Kompas Sulsel dalam paket berita kisruh Kerajaan Gowa, keduanya sama - sama menggunakan format VO/SOT dan Format Paket [package]. Dimana paket berita yang ditayangkan merupakan laporan berita lengkap dan telah melalui editor berita dalam tahap produksinya.

Penyajian berita Kisruh Raja Gowa pada Inews-sulsel lebih sensasional dibandingkan dengan Kompas-sulsel. Inews-sulsel lebih sensasional dalam lima kategori, diantaranya, penamapilan emosi, penggunaan teknik eyewitness camera, penggunaan suara natural, penggunaan teknik zoom, dan pengemasan paket berita yang banyak 
menggunakan teknik editing [efek transisional dan non transisional].

\section{B. Saran}

Perlu adanya pendidikan dan pemahaman jurnlaistik terutama mengenai sensasionalisme bagi para jurnalis televisi [newsanchor, reporter, camera person, editor, dan tim redaksi lain yang bertanggung jawab dalam penayangan berita]. Sedikitnya syarat berupa pendidikan atau background jurnalistik bagi para jurnalis membuat mereka berlomba lomba untuk membuat berita yang menarik perhatian. Pengetahuan dan kemampuan jurnalis akan menentukan informasi apa yang nantinya akan diserap oleh masyarakat setelah menyaksikan berita tersebut.

Tidak hanya tampil visual saja yang harus diperhatikan oleh para jurnalis televisi. Elemen audio baik berupa musik maupun narasi suatu berita juga harus diperhatikan. Terkadang musik yang ditempelkan pada paket berita membuat berita tersebut layaknya film yang menegangkan bagi penonton. Penggunaan efek yang berlebihan ini memiliki efek negatif berupa terganggunya penerimaan informasi oleh khalayak [penonton].

\section{REFERENSI}

\section{References}

Baksin. (2006). Retrieved from http://xerma.blogspot.co.id/20 13/08/pengertian-televisimenurut-para-ahli.html?m=1

Berkowitz, \& Gobetz, S. \&. (1993;1992). Explicating sensasionalism in television News. Nijmegen, Netherlans: Tandem Felix.

Grabe, \& Barnett. (2001). www.digilib.lib.ui. Retrieved from http://pengertiandefenisi.com/ pengertian-berita-defenisiunsur-dan-jenis-berita/

Greenfield. (1996). Retrieved from http://xerma.blogspot.co.id/20 13/08/pengertian-televisimenurut-para-ahli.html?m=1

Kruger. (1996). Retrieved from http://xerma.blogspot.co.id/20 13/08/pengertian-televisimenurut-para-ahli.html?m=1

Mulyana, D. d. (2007). Metode Penelitian Komunikasi. Bandung: Remaja Rosda Karya.

NewHagen, \& Grimm. (1998;1996). www.digilib.lib.ui. Retrieved from http://pengertiandefenisi.com/ pengertian-berita-defenisiunsur-dan-jenis-berita/

Postman, N. (1995). Menghibur Diri Sampai Mati : Mewaspadai Media Televisi. Jakarta: Pustaka Sinar Harapan.

Septian, S. K. (2005). urnalisme Kontemporer. Jakarta: Yayasan Obor Indonesia.

Vettehen, P. B. (2006). News is an Age of Competition: Sensasionalism in Dutch Television News 1995 2001.

Zhou, S. (2001). Explicating Sensasionalism inTelevision News: Contentand the Bells and Ehistles of Form. Journal of Broadcasting \& Electronic Media. . 